\title{
REFLEX INHIBITION OF COLD SHIVERING BY PRESSURE ON THE EYE-BALL AND THE EAR-ROOT OF THE RABBIT, AND ITS AFFERENT PATHWAY
}

\author{
Mitsuo KoSAKA \\ Department of Physiology, Nagoya University School of Medicine, Nagoya
}

Recently, considerable interest has been attracted to the problem of non-specific inhibition of vegetative and extrapyramidal motor regulatory processes concerned with thermo-regulation, such as sweating and cold shivering. "Hemihidrotic phenomenon," that is the inhibition of sweating in human beings as a consequence of postural change ${ }^{19,24)}$ has been experimentally studied and proved to be the effect of mechanical pressure applied on the $\operatorname{skin}^{15,30)}$. The central mechanism of the "skin pressure reflex" has not yet been clarified conclusively ${ }^{21)}$, because of the difficulty of estimation of an autonomic function such as sweating in the unanaesthetized unrestrained animals. However, recent reports ${ }^{16,29,31)}$ indicating that cold shivering was markedly inhibited by mechanical pressure on the eye-ball or the skin, gave us a clue to solve a certain part of the central mechanism concerned with the reflex inhibition. Further observation on the inhibitory effect on cold shivering due to pressure on the eye-ball and the ear-root of the rabbit is described in this paper.

\section{METHODS}

25 albino rabbits ( $3-4 \mathrm{Kg}$ body weight) were used for this experiment. Unanaesthetized rabbits lightly restrained in prone position were exposed in a cold environment (room temperature : $5-10^{\circ} \mathrm{C}$, and its humidity : $60 \%$ ) to produce cold shivering, which was recorded electromyographically from the bilateral M. triceps brachii of the forearm.

In some cases, ECG and heart rate were also polygraphically demonstrated. The heart rate meter was designed in principle so that the larger amplitude coincides with the longer time interval of the RR spike of the ECG. EEGs of the motor and limbic
cortex were recorded and their frequency spectra, namely, 2-4 c/s (delta), $4-8 \mathrm{c} / \mathrm{s}$ cortex were recorded and their frequency spectra, nam, $8-13 \mathrm{c} / \mathrm{s}$ (alpha), $13-20 \mathrm{c} / \mathrm{s}$ (beta-1) and $20-30 \mathrm{c} / \mathrm{s}$ (beta-2), were demonstrated on the same record, integrated every $10 \mathrm{sec}$ by means of an automatic frequency analyser (Nihonkoden Kogyo Co.).

Received for publication March 21, 1968

小坂光男 
A mechanical pressure stimulus, of about $200 \mathrm{~g} / \mathrm{cm}^{2}$ was applied by means of an opthalmodyanomometer on the eye-ball. Pressure of about $3 \mathrm{Kg} / 20 \mathrm{~cm}^{2}$ was applied to the ear-root by pinching with a hinged paper holder, mantled by rubber so as not to cause pain.

The spinal trigeminal tract was electrically stimulated at a point about $5 \mathrm{~mm}$ below the obex with repetitive pulses of $5-80 \mathrm{c} / \mathrm{s}, 0.5 \mathrm{msec}$ duration, and $0.1-3.0$ volts intensity. The stimulating electrode was a single coated steel wire of a diameter below $5 \mu$ at the tip. In some cases, bilateral vagal nerves (with cardiac branches) were cut at the upper part of the neck, and one or both sides of the carotid artery were occluded with small artery clamps. The descending spinal tract of the trigeminal nerve was dissected at 3-5 mm below the obex with a tiny semilunar knife for the corneotomy. The surgical procedure of the spinal trigeminal tract was performed referring to the atlas of MeEssen and OlszewsKi ${ }^{22)}$.

\section{RESULTS}

In a cold environment, when shivering started in the rabbit, it frequently occurred as a shudder in accordance with each inspiration. Such moderate shivering was markedly inhibited or disappeared simultaneously with the onset of pressure stimulation on the eye-ball and continued to be inhibited throughout during stimulation as shown in FIG. 1. The inhibitory effect on cold shivering and coincidently a marked bradycardia were observed in all cases where the shivering was not too intense (H. R. in FIG. 1). Marked changes

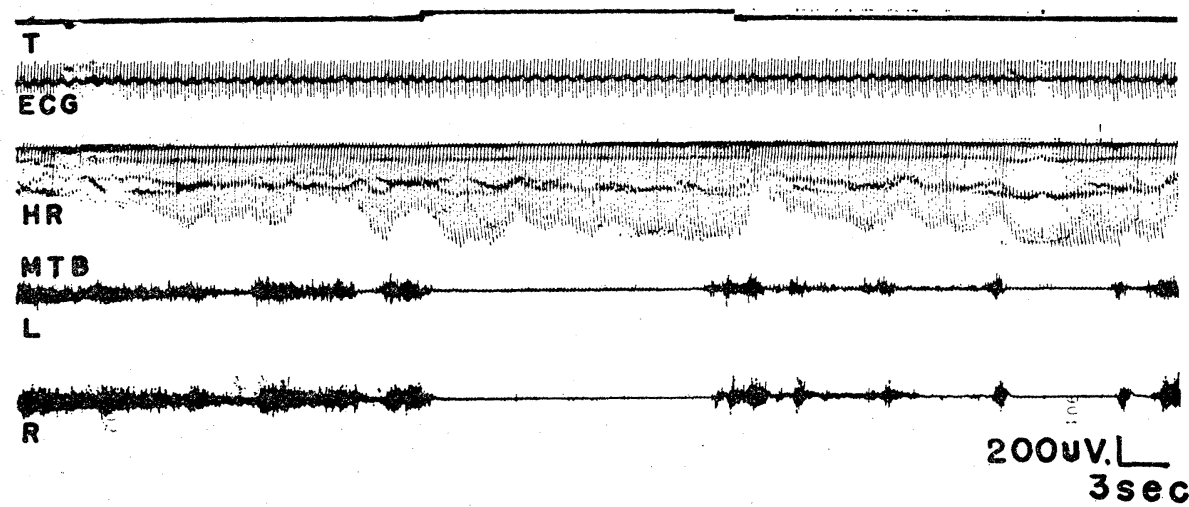

FIG. 1. Reflex inhibition of cold shivering and heart rate by pressure on the eye-balls in the rabbit. T., stimulus mark; upward deflexion indicates the application of a pressure of about $200 \mathrm{~g} / \mathrm{cm}^{2}$. Downward excursion of the heart rate recording (HR) shows slowing down of the heart rate. MTB L and R; Electromyogram of the $M$. triceps brachii of left and right side respectively.

were observed in EEGs and in frequency spectra especially of the motor cortex (M. C. in FIG. 2) associated with the inhibition of shivering throughout the pressure stimulation: Cortical activity was kept as constant as possible, 


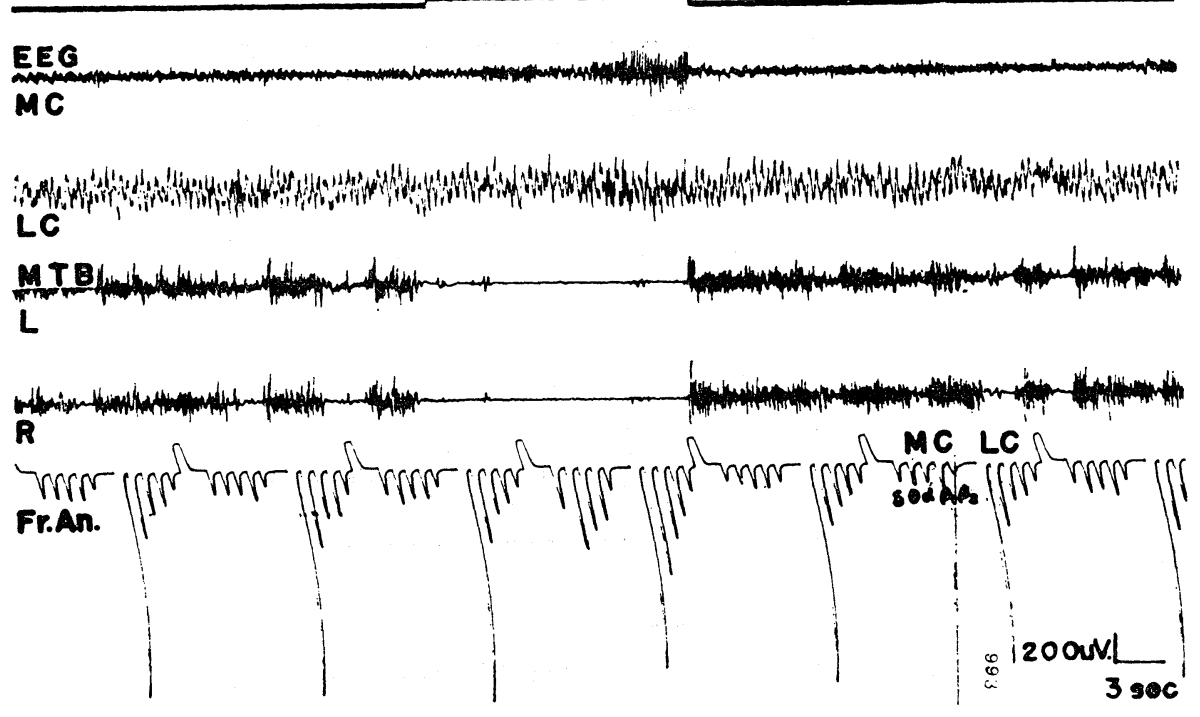

FIG. 2. Reflex inhibition of cold shivering and cortical function by pressure on the eye-balls in the rabbit. EEG.; electroencephalogram of motor (MC) and limbic (LC) cortex. Fr. An., Frequency specta of five band $\left(\delta, \theta, \alpha, \beta_{1}, \beta_{2}\right)$ of EEG of motor (MC) and limbic (LC) cortex.

in an aroused state by previous prolonged exposure to a certain cold environment, in order to distinguish the changes in EEG pattern elicited by pressure stimulation. About 10-15 sec. after application of mechanical pressure on the eye-ball, the aroused pattern of the motor cortex, characterized by a persisting low voltages and desynchronization, was replaced by a high voltages spindle wave, while the synchronized limbic aroused pattern was replaced by an irregular desynchronization pattern. Frequency spectra of EEG wave indicated that in all five spectra of the motor cortex, the integrated magnitudes of the record were increased, while in the limbic cortex, these magnitudes decreased in the delta band, and increased in the other four specta. The result indicates that the cortical function was also deactivated by pressure on the eye-ball as well as on the skin reported in the similar investigation of KumAzAwA ${ }^{18}$. To answer the question whether the inhibitory effect on shivering of pressure is a secondary reaction caused by changes in circulatory system or not, the following experiment was performed: In addition to occlusion of the carotid artery on one side, when both vagi (with afferent cardiac branches) were cut at the upper part of the neck, the burst rhythm of the shivering turned to a more regular one of about $5 \mathrm{sec}$. period as shown in FIG. 3-A. Under these conditions, bilateral mechanical pressure on the eye-ball (B) remained effective in inhibiting cold shivering. When the other common carotid artery was occluded at the mark $(1 \downarrow)$ in FIG. 3-C, the regular period of burst was changed to 


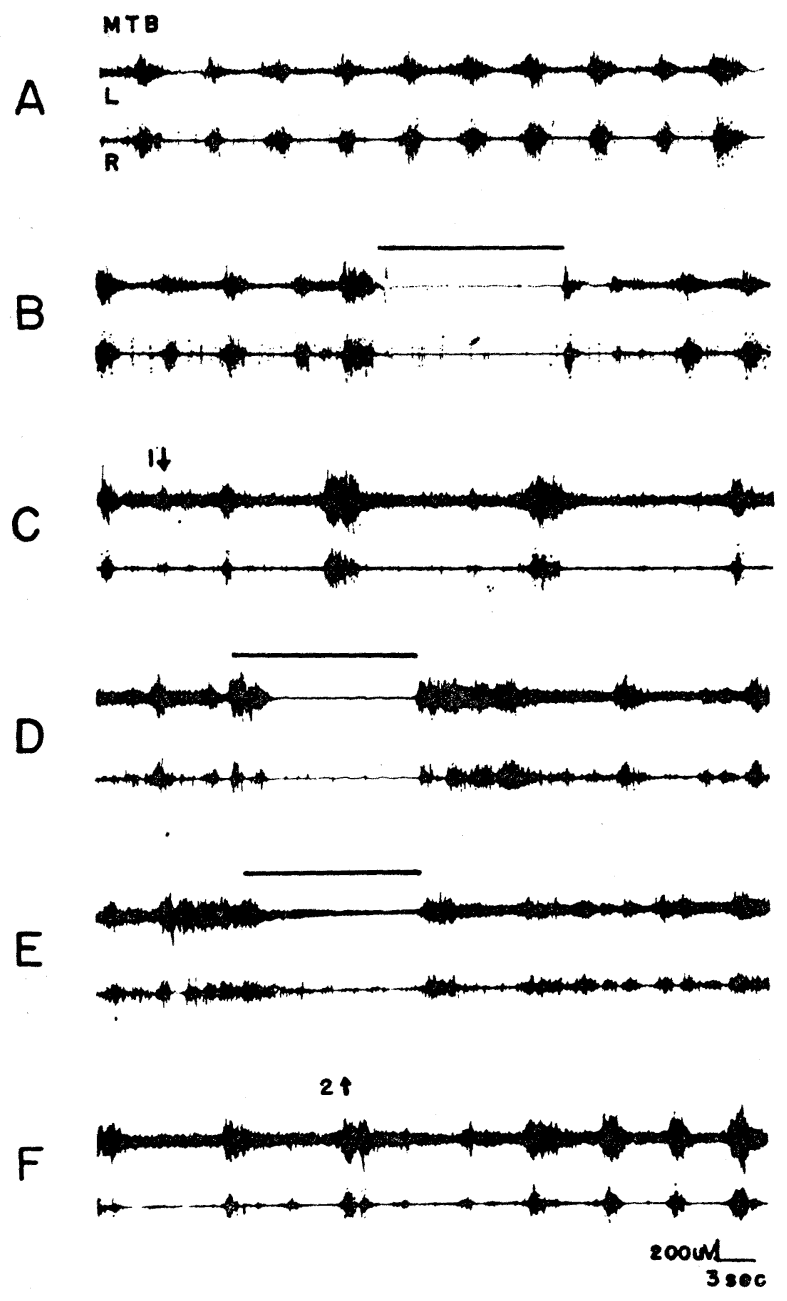

FIG. 3. Reflex inhibition of cold shivering by application of pressure on the eye-balls and the ear-roots and function of sinus nerves and vagal nerves. A., occurrence of regular bursts of shivering after cutting both vagi and the occlusion of one common carotid artery. B., application of pressure on the eye-balls under condition A. C., the other common carotid artery was occluded at $1 \downarrow$. D. and E., under condition $C$ pressure stimuli were applied on the eye-balls and on the ear-root respectively. F., one common carotid artery was released from occlusion at $2 \uparrow$.

an irregular, longer time interval of about $10-15 \mathrm{sec}$. With these conditions, mechanical pressure on the eye-ball (D) or the ear-root (E) was also effective in inhibiting shivering. At the mark $(2 \uparrow)$ indicated in FIG. $3-F$, occlusion of the carotid artery was released the shivering returning to the original regular burst rhythm again. The result indicates that the inhibitory effect on shivering 
due to pressure applied on the eye-ball or the ear-root appears independently of the reaction of afferent vagal and carotid sinus stimulation.

Some experiments were performed to identify the reflex afferent pathway in the spinal cord. Rabbits had been subjected to a partial cordotomy at 3-5 $\mathrm{mm}$ below the obex of the medulla oblongata to cut off the descending spinal trigeminal tract on one side. In the experiment of FIG. 4 where the tract had been cut on the right side, the inhibitory effect on shivering and heart rate remained intact, when the pressure stimulus was applied on the left eye-ball at $\mathrm{A}$ or on the left ear-root at B, while no effect was obtained when applied on the right eye-ball at $\mathrm{C}$ or on the right ear-root at $\mathrm{D}$.
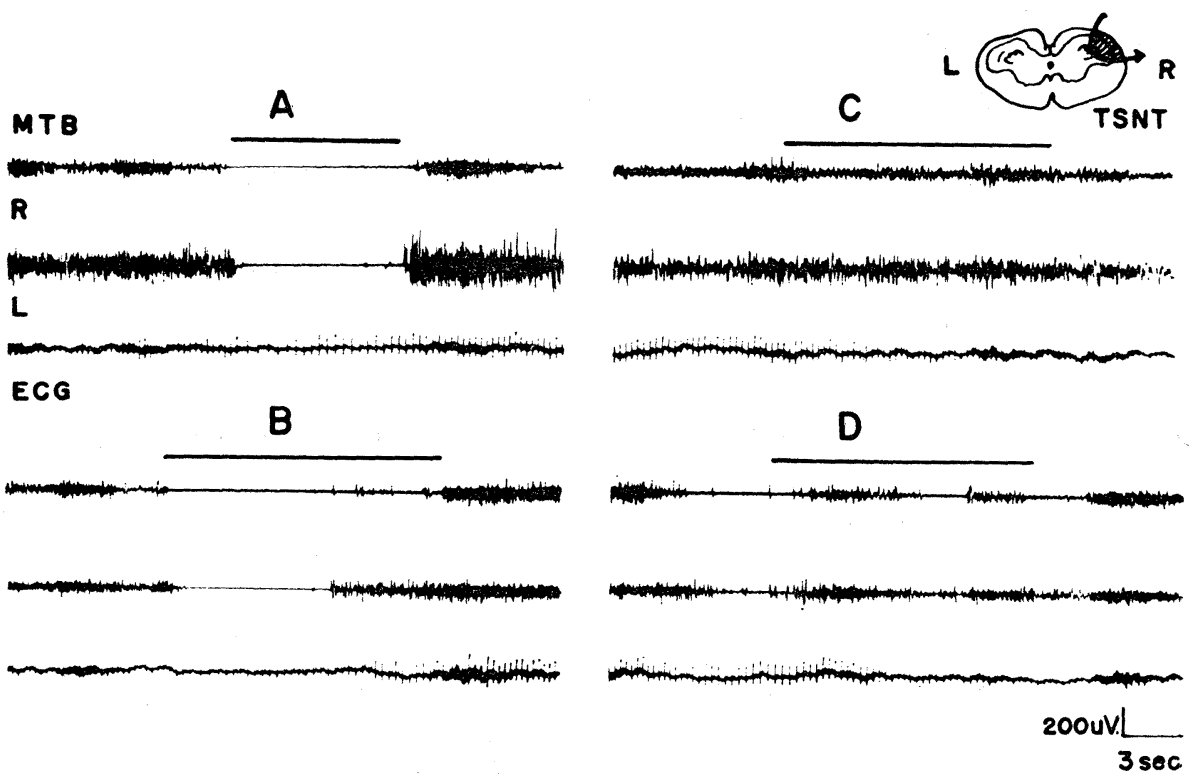

FIG. 4. The effect of the transection of the spinal trigeminal tract upon reflex inhibition of cold shivering. The tractotomy had been done in the right side at the level of $3-5 \mathrm{~mm}$ below from the obex of the medulla. Bars above each figure show pressure application on the left eye-ball in $A$, on the left ear-root in $B$, on the right eye-ball in $\mathrm{C}$. and on the right ear-root respectively.

The result indicates that the afferent signals of this reflex do not pass through the pathway which terminates directly at the main sensory trigeminal nucleus in the pons, but through the descending spinal tract of the trigeminal nerve to change the neuron in the spinal cord.

A similar inhibitory effect on shivering was observed with electrical stimulation of the spinal trigeminal tract. At the beginning, various parameters for stimulation were tried in order to find an adequate one for inhibition. The results obtained from 5 rabbits indicates that an adequate parameter for the inhibitory effect on shivering is concentrated at the low frequency under 
$0.5 \mathrm{msec}$ duration and 1 volt intensity. This belongs to the parameter range which evokes selectively GII or GIII fibers in the peripheral nerve to be excited. FIG. 5 shows a recording of the inhibitory of facilitory effect on shivering by electrical stimulation of the spinal trigeminal tract of the right side under the parameters shown in the figure. In three cases (A, B and $C$ ), the inhibitory effect on shivering was observed to be somewhat stronger in the muscle of the ipsilateral side of the stimulation than in that of the contralateral side. The tendency of laterality of the inhibitory effect on shivering was, however, not always observed, if the EMG of shivering were recorded in the trunk

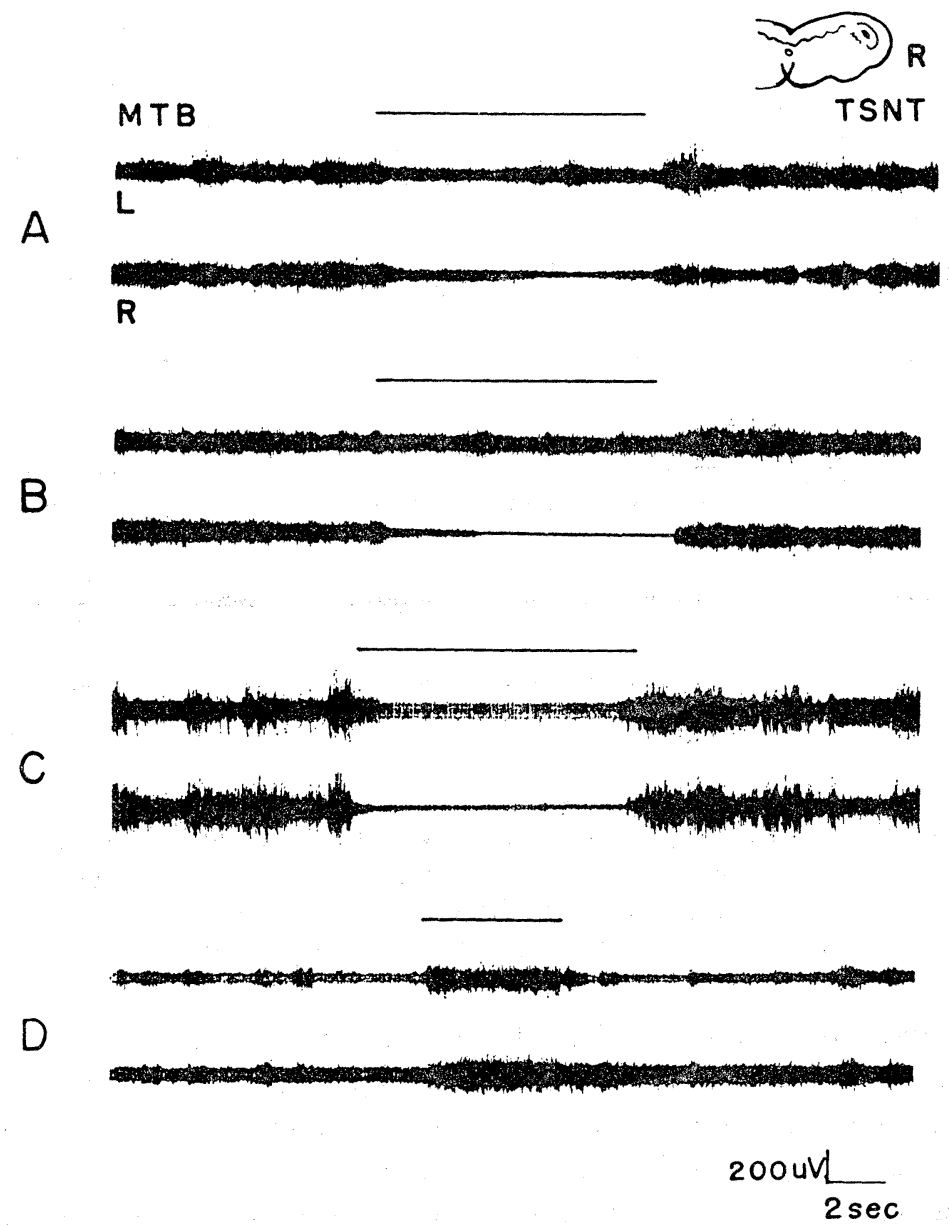

FIG. 5. Reflex inhibition and facilitation of cold shivering by electrical stimulation of the spinal trigeminal tract on the right side. Bars above each figure indicate application of square wave pulses of $0.5 \mathrm{msec}$. duration and $1 \mathrm{~V}$. intensity at the frequency of $5 / \mathrm{sec}$. (A), $8 / \mathrm{sec}$. (B), $15 / \mathrm{sec}$ (C) and $50 / \mathrm{sec}$. (D), respectively. 
muscles. On the other hand, the facilitory effect on shivering was observed in the stimulation of higher frequency as shown in (D), which suggests the possibility of the existence of at least two functionally antagonistic fiber-groups in the spinal trigeminal tract.

\section{DISCUSSION}

The depressive effect on cardiac and respiratory functions of pressure stimulus applied on the eye-ball is well known as Aschner's phenomenon which is indicative of cardiac vagal effect through the nervous reflex. It is obvious in this case that the trigeminal nerve plays an important role as the afferent pathway in the oculo-cardiac reflex. Recent investigations on the nervous reflex of shivering, from the carotid sinus ${ }^{13,14}$, indicated that baroreceptor stimulation caused by raising the internal pressure in the isolated innervated carotid sinus elicited shivering and cold shivering was not observed when the arterial pressure was lower than $70 \mathrm{mmHg}$, even if the rabbit was exposed for a long time to the cold environment.

MoTT ${ }^{23)}$ demonstrated that weak electrical stimulation of the central end of the depressor nerve in the neck of the rabbit augmented cold shivering, but strong stimulation stopped it without a rise of arterial pressure. Even when the sinus and depressor nerve function was blocked by cutting, the inhibitory effect on shivering was still observed when pressure was applied on the eye-ball or the ear-root. These results may lead us to the following conclusion that the secondary depressive effect on cold shivering of the buffer nerve, due to primary fall in blood pressure, can be left out of consideration in the present investigation. The afferent impulses from the stimulated area are conducted through the trigeminal nerve to inhibit directly the shivering through some reflex center. Therefore, the following discussion will be concerned mainly with the trigeminal tracts as the reflex afferent pathway.

It is quite obvious that pain, temperature and touch-pressure sensations of the face and buccal cavity are served by the trigeminal nerve. Previous investigations $\mathbf{6}^{6,27,28,34)}$ indicating that the fibers which pass down the spinal trigeminal tract relay the appreciation of pain and temperature, while those which terminate at the main sensory nucleus carry the sensation of touch and proprioception, have been somewhat revised by recent investigations ${ }^{2,5,7,8)}$. These investigators agreed in their observation that the nucleus of the spinal trigeminal tract shows the features of a typical tactile relay nucleus and it was reported that a large number of tactile impulses were traced into the spinal trigeminal tract as far as the lower medulla and the first cervical segment ${ }^{8)}$ or to the level of the C-1 and C-2 segment ${ }^{22}$.

Recently EISENMAN, LANGREN and Novin ${ }^{5)}$ found in their precise experiment that there are two groups of cells in the nucleus tractus spinalis oralis. 
These cells which correspond to the cells "A " reported by GoRDON et al. ${ }^{7}$, respond only to touch or only to moderate pressure applied on the face, but do not respond to noxious, thermal or gustatory stimuli. The reports suggest the existence of specific fibers within the spinal trigeminal tract, which carry only the impulses of pressure or touch-pressure sensation.

The present findings illustrated in FIG. 4 show that the inhibitory effect on shivering of pressure stimulus on the unilateral eye-ball vanishes completely, when the spinal trigeminal tract is transected at the level of $C_{1}$ on the same side. This result indicates that the inhibitory afferent impulses, elicited by pressure on the face, run down through the spinal trigeminal tract on the ipsilateral side, which corresponds to the primary neuron of the anterior spinothalamic tract for the trunk region, but do not terminate directly at the main trigeminal nucleus.

Identification of anatomical, physiological characteristics of GII or GIII fibers in the peripheral nerve has been studied by MARUHASHI, MizUGUCHI and TASAKI ${ }^{20)}$ and HUNT and MCINTYRE ${ }^{11)}$ and by many other investigators. However, the interpretation of the function of GII or GIII fibers has been yet not clarified conclusively. DODT ${ }^{3,4)}$, and HENSEL and ZOTTERMAN ${ }^{10)}$ showed that some single afferent fibers from the tongue of the cat can be activated by tactile as well as by thermal stimuli within the physiological range. The diameter of specific pain fibers in the lingnal nerve of the cat which could be activated by temperature changes of the tongue were calculated to be $3-7 \mu^{3)}$. These fibers, therefore, may belong to GII or GIII fibers. PAINTAL ${ }^{25}$ ) showed that GIII fibers in muscles of the cat produced several depressive reflex effects on cardiovascular functions activated by strong mechanical pressure on chemical stimulus to the muscle (which clearly produces a severe pain sensation in man).

These investigations ${ }^{3,4,10,25)}$ indicating that the GII or GIII fibers might be activated not only by pain but also by thermal or in some cases touch-pressure stimuli, agreed with the observations of HUNT and MCINTYRE ${ }^{12)}$ and WITT and HENSEL $^{35)}$, and the earlier observations of WALKER $^{32)}$ for the trigeminal nerve. These investigations may suggest that the small fibers group (GII-GIII) in the spinal trigeminal tract conducting the impulses of pressure, touch-pressure can play an important role in the reflex inhibition of cold shivering by pressure applied on the face.

A concept of epicritic and protopathic sensibility was first described by $\mathrm{HEAD}^{9)}$ who postulated that fine intensity and spatial discrimination was concerned with epicritic sensation, and on the other hand, the phylogenetically older protopathic system was concerned with the more primitive and crude sensations. WALKER ${ }^{33)}$ supported this concept and described the topographic organization in the spinal cord of these different sensations: Pressure sensation served by the phylogenetically newer dorsal funiculus is concerned with 
epicritic and discriminative sensation, while that by the phylogenetically older ventral funiculus seems to be protopathic.

KosAKA, TAKAgI and KoYAmA ${ }^{17)}$ proved in the rabbit experiments that the impulses producing the inhibitory effect on shivering when pressure was applied on the skin, ascend within the ventral funiculus, not within the dorsal funiculus.

If the result presented would be compared with Walker's result, it might be most probable that the phylogenetic older ventral funiculus would serve mainly as the reflex afferent rather than as a pathway for the epicritic sensation. The observation of BROUWER ${ }^{1)}$ that the relative area in the spinal cord occupied by the ventral funiculus is larger than the area occupied by the dorsal funiculus in the lower animals, but not in the highly developed, may support the assumption above mentioned. The fact that destruction of the anterolateral column alone does not lead to any defects or only to a slight impairment in tactile sensation ${ }^{26)}$ could be another evidence for this suggestion.

\section{SUMMARY}

1. Reflex inhibition of cold shivering due to mechanical pressure applied on the face on the rabbit and its primary afferent pathway in the central nervous system was studied to clarify the mechanism of the "skin pressure reflex."

2. Mechanical pressure on the eye-ball and the ear-root was greatly effective in inhibiting cold shivering.

3. The spinal trigeminal tract is the afferent pathway of the reflex inhibition of shivering by pressure on the face, that was proved by the tractotomy of the trigeminal nerve in the spinal cord.

4. The trigeminal fibers entering directly to the main sensory nucleus is not associated with the reflex inhibition. Small fibers of the spinal trigeminal tract, considered as GII or GIII fibers from the result parameter of electrical stimulation of the tract, might play an important role in conducting the impulses evoked by pressure applied to the face.

5. Phylogenetical aspects of the spinal cord and the anatomical, functional characteristics of the peripheral nerve were discussed in relation to the mechanism of the "skin pressure reflex."

The author would like to express acknowledgment and gratitude to Prof. K. TAKAGI for his guidance and helpful advice during the course of this investigation.

\section{REFERENCES}

1) Brouwer, B. Anatomical, phylogenetical, and clinical studies on the central nervous system. (The John Hopkins Univ. lectures on the Herter Fundation, The Williams and Wilkins Comp. Baltimore), 1927.

2) Darian-Smith, I., Mutton, P. And Procter, R. Functional organization of 
tractile cutaneous afferent within the semilunar ganglion and trigeminal spinal tract of the cat. J. Neurophysiol., $28: 682,1956$.

3) DodT, E. Schmerzimpulse bei Temperaturreizen. Acta physiol. scand., $31: 83$, 1954.

4) Dodt, E. Differential thermosensitivity of mammalian A-fibers. Acta physiol. scand., 29 : 91, 1953.

5) Eisemna, J., Landgren, S. And Novin, D. Functional organization in the main sensory trigeminal nucleus and it the rostral subdivision of the nucleus of the spinal trigeminal tract in the cat. Acta physiol. scand., 59 : Suppl. 214, 1963.

6) Gerard, M.H. Afferent impulses of the trigeminal nerve. Arch. Neurol. Psychiat., Chicago, 9: 306, 1923.

7) Gordon, G., Landgren, S. And Seed, W.A. The functional characteristics of single cells in the caudal part of the spinal nucleus of the trigeminal nerve of the cat. J. Physiol., $158: 544,1961$.

8) Harrison, F. ANd Corbin, K.B. Oscillographic studies on the spinal tract of the fifth cranial nerve. J. Neurophysiol., $5: 465,1942$.

9) Head, H. Studies in neurology. London, Oxford Univ. Press., 1920.

10) Hensel, H. and Zotterman, Y. The response of mechanoreceptors to thermal stimulation. J. Physiol., 115 : 16, 1951a.

11) Hunt, C.C. And McIntyre, A.K. An analysis of fibre diameter and receptor characteristics of myelinated cutaneous afferent fibres in cat. J. Physiol., 153: 99, 1960.

12) Hunt, C.C. And McIntyre, A.K. Properties of cutaneous touch receptors in cat. J. Physiol., 153: 88, 1960.

13) IshiI, K. AND IsHir, K. Carotid sinus reflex acting upon shivering. Tohoku J. Exptl. Med. (Japan), $72: 229,1960$.

14) IshII, K. AND IsHI, K. Relation to blood pressure to shivering. Tohoku J. Exptl. Med. (Japan), $72: 237,1960$.

15) Kawase, T. Further studies on "pressure sweat reflex". Jap. J. Physiol., $3: 1$, 1952.

16) Kosaka, M., Yamamoto, S. And Takagi, K. Reflex inhibition of shivering due to pressure applied to the skin. Report I: Afferent spinal pathway. Int. J. Biometeor., 3: 86, 1964.

17) Kosaka, M., Takagi, K. And Koyama, Y. Reflex inhibition of shivering by pressure to the skin and the histological investigation of its afferent spinal pathway. Experientia, 23: 453, 1967.

18) Kumazawa, T. "Deactivation" of the rabbit's brain by pressure application to the skin. EEG clin. Neurophysiol., 15:660, 1963.

19) Kuno, Y. Human perspiration. Thomas, Springfield, 1956.

20) Maruhashi, J., Mizuguchi, K. ANd Tasaki, I. Action currents in single afferent nerve fibers elicited by stimulation of the skin of the toad and the cat. J. Physiol., $117: 129,1952$.

21) Matsumoto, $Y$. On the central pathway of the pressure-sweating-reflex in cats. (in Japanese) J. Physiol. Soc. Jap., 17: 263, 1955.

22) Meessen, H. And Olszewski, J. Cytoarchiterktonischer Atlas des Rautenhirns des Kaninchens. S. Karger, Basel, 1949.

23) Mотт, J.C. The effects of baroreceptor and chemoreceptor stimulation on shivering. J. Physiol., 166 : 563, 1963.

24) Ogata, K. and Ichinashi, T. J. orient. Med. (in Japanese), $23:$ 1127, 1935.

25) Paintal, A.S. Functional analysis of GII afferent fibers of mammalian muscles. J. Physiol., 152: 250, 1960. 
26) Rose, J.E. And Mountcastle, V.B. Touch and Kinesthesis, Handbook of Physiology, Sect. 1., Neurophysiology. Vol. 1. Amer. Physiol. Soc. 1959, 416-417.

27) SJöqvist, O. Studies of pain conduction in the trigeminal nerve. Acta psychiat. scand. Suppl., $17: 1,1938$.

28) Spiller, W.G. Remarks on the central representation of sensation. J. nerv. ment. Dis., 42 : 399, 1915.

29) Takagi, K. and Hasegawa, A. ibid., 1:315, 1954.

30) TAKAgI, K. AND SAKurai, T. A sweat reflex due to pressure on the body surface. Jap. J. Physiol., $1: 22,1950$.

31) Takagi, K., Yamamoto, S. And Kosaka, M. Reflex inhibition of cold shivering by pressure to the skin. Report II : Afferent spinal pathway. J. Physiol. Soc. Jap. (in Japanese), $26: 483,1964$.

32) WAlker, A.E. Anatomy, physiology and surgical considerations of the trigeminal nerve. J. Neurophysiol., $2: 234,1939$.

33) Walker, A.E. The spino-thalamic tract in man. Arch. Neurol. Psychiat., 43: 284, 1940.

34) Winkler, C. A case of occlusion of the arteria cerebelli posterior inferior. Proc. Acad. Sci. Amst. (Sect. Sci.), $17:$ 914, 1915.

35) Witt, I. And Hensel, H. Afferent Impulse aus der Extremitätenhaut Pflügers Arch., 268 : 582, 1959. 